\title{
Ménétrier-like disease in a Pointer with concurrent granulomatous gastritis, helicobacteriosis and leishmaniosis: a case report
}

E. Lagerstedt ${ }^{1 *}$, T. Spillmann ${ }^{1}$, N. Airas ${ }^{2}$, L. Solano-Gallego ${ }^{3}$ and S. Kilpinen ${ }^{1}$

\begin{abstract}
Background: Ménétrier-like disease is a rare hypertrophic canine gastropathy, reported in only seven dogs. Clinical signs are vomiting, anorexia and weight loss. Macroscopically, giant cerebriform gastric mucosal folds are typically seen in the corpus and fundus of the stomach. Histopathologically, fundic mucous cell hyperplasia and loss of parietal and chief cells are typical.

Case presentation: A nine-year-old spayed female Pointer had a history of intermittent vomiting, marked weight loss and hypoalbuminaemia. A gastroduodenoscopy was performed three times within three months with macroscopic changes remaining the same. The gastric mucosa of the corpus, fundus and proximal antrum was markedly irregular, with cerebriform mucosal folds. In the first gastric biopsies, histopathology revealed a moderate granulomatous gastritis, with a severe manifestation of Helicobacter-like organisms. Treatment for Helicobacter spp. decreased the vomiting slightly. The dog was diagnosed with concurrent leishmaniosis; the conventional antiLeishmania treatment decreased the vomiting moderately, the hypoalbuminaemia resolved and the dog gained weight back to a normal body condition. Granulomatous gastritis was not present in the gastric biopsies after these treatments. The dog increased vomiting when palliative treatment (maropitant citrate, ondansetron and esomeprazole) was discontinued, and thus, full-thickness biopsies of the stomach were taken and Ménétrier-like disease was diagnosed. The affected area was too large to be surgically removed; thus, palliative treatment was reinstated. The dog remained clinically well 39 months after the first clinical presentation.

\footnotetext{
* Correspondence: emma.lagerstedt@helsinki.fi

'Department of Equine and Small Animal Medicine, Faculty of Veterinary Medicine, University of Helsinki, P.O. Box 57, Fl-00014 Helsinki, Finland

Full list of author information is available at the end of the article
}

(c) The Author(s). 2021 Open Access This article is licensed under a Creative Commons Attribution 4.0 International License, which permits use, sharing, adaptation, distribution and reproduction in any medium or format, as long as you give appropriate credit to the original author(s) and the source, provide a link to the Creative Commons licence, and indicate if changes were made. The images or other third party material in this article are included in the article's Creative Commons licence, unless indicated otherwise in a credit line to the material. If material is not included in the article's Creative Commons licence and your intended use is not permitted by statutory regulation or exceeds the permitted use, you will need to obtain permission directly from the copyright holder. To view a copy of this licence, visit http://creativecommons.org/licenses/by/4.0/. The Creative Commons Public Domain Dedication waiver (http://creativecommons.org/publicdomain/zero/1.0/) applies to the data made available in this article, unless otherwise stated in a credit line to the data. 


\begin{abstract}
(Continued from previous page)
Conclusions: This is the first report of Ménétrier-like disease in a dog with a simultaneous manifestation of granulomatous gastritis, helicobacteriosis and leishmaniosis. The clinical signs decreased after treatment of helicobacteriosis and leishmaniosis, but vomiting remained probably as a sign of Ménétrier-like disease. Treatment options for dogs are surgical removal of the abnormal area or palliative treatment. In humans, promising results for a cure have been shown with cetuximab treatment, a human monoclonal antibody, but no canine antibody is commercially available yet. The dog here was doing well 39 months after first presentation, which is the longest reported survival time for Ménétrier-like disease with only palliative treatment in dogs. Full-thickness biopsies are preferred in macroscopic hypertrophic lesions of the stomach for better assessment of Ménétrier-like disease.
\end{abstract}

Keywords: Ménétrier's-like disease, Menetrier's disease, Giant hypertrophic gastritis, Helicobacter spp., Leishmania, Foveolar hyperplasia

\section{Background}

Ménétrier's disease (MD) is a rare hypertrophic gastropathy in humans, characterized macroscopically by giant cerebriform gastric mucosal folds in the corpus and fundus of the stomach, sparing the antrum and pylorus $[1$, 2]. Histopathologically, hyperplasia of the mucous cells within the neck and base areas of the fundic glands and loss of parietal and chief cells are typical [1]. The criteria for diagnosis of MD in dogs have not yet been established in detail, which is why the term Ménétrier-like disease (MLD), instead of MD, is preferred in dogs. MLD has been reported earlier in only seven dogs representing five different breeds: a Boxer, an Old English Sheepdog, a West Highland White Terrier, three Cairn Terrier littermates and a Jack Russell Terrier [3-7]. In all reported canine cases, hyperplasia of the mucous cells in the corpus and fundus of the stomach was described, and in four cases also the loss of parietal and chief cells $[6,7]$. The most common clinical signs and findings in affected dogs include vomiting, anorexia, weight loss and hypoalbuminaemia [3-7]. The aetiology underlying MLD in dogs is unknown, but in humans and mice, one factor in the pathogenesis of MD is suggested to be increased signalling of epidermal growth factor receptors (EGFR) [1]. In humans, MD usually shows chronic progressive features, but variants with acute onset and spontaneous remission have been reported, and have been associated with Helicobacter pylori infection in adults and cytomegalovirus (CMV) infection in children [2, 8]. This report describes for the first time the coexistence of MLD with granulomatous gastritis, a severe manifestation of Helicobacter-like organisms and leishmaniosis in a Pointer.

\section{Case presentation}

A nine-year-old spayed female Pointer weighing $15 \mathrm{~kg}$ was presented with a nine-month history of intermittent vomiting and marked weight loss to the University of Helsinki Veterinary Teaching Hospital, Finland. The dog was born in Greece and had lived one year in Germany before moving to Finland six years before presentation. On physical examination, the dog's body condition score was $3 / 9$ and it had mild periodontitis.

Complete blood count results were within reference intervals. Serum biochemical abnormalities included mild hypoproteinaemia, mild hypoalbuminaemia and hypocobalaminaemia. C-reactive protein was mildly elevated. Antibody titres against Leishmania infantum antigens (immunofluorescence antibody test, Ludwig Maximilian University of Munich) were markedly elevated (Table 1). Serum gastrin concentration was $26 \mathrm{ng} / \mathrm{l}$ (reference interval 10-40 ng/l, Michigan State University). To rule out hypoadrenocorticism, basal serum cortisol concentration was measured and it was $34 \mathrm{nmol} / \mathrm{l}$ (reference interval 10-100 nmol/l, IDEXX Laboratories) [9]. Serum Dirofilaria immitis antigen and antibodies against Borrelia burgdorferi, Anaplasma phagocytophilum and Ehrlichia canis were negative (SNAP 4Dx, IDEXX Laboratories).

Faecal examination for endoparasites by flotation, antigen testing for Giardia duodenalis (FASTest Giardia) and bacterial culture for Yersinia spp., Salmonella spp., Campylobacter spp., Clostridium difficile and Clostridium perfringens were negative. Urinalysis including urine protein-creatinine ratio was unremarkable. Abdominal ultrasonography revealed a partial mild gastric wall thickening with slight loss of wall layering, mild thickening of the colonic wall with normal wall layering, enlarged and slightly heterogenic medial iliac lymph nodes, prominent mesenteric lymph nodes and hyperechoic sports in both renal cortices.

To exclude food-responsive enteropathy, an elimination diet was started with a hydrolysed diet in addition to palliative treatment comprising famotidine (Pepcid; Janssen-Cilag, $0.7 \mathrm{mg} / \mathrm{kg}$ orally $\mathrm{q} 12 \mathrm{~h}$ ), ondansetron (Ondansetron Stada; Stada Arzneimittel, $0.3 \mathrm{mg} / \mathrm{kg}$ orally $\mathrm{q} 8 \mathrm{~h}$ ) and maropitant citrate (Cerenia; Zoetis, $3.2 \mathrm{mg} / \mathrm{kg}$ orally q24h). Cobalamin supplementation was initiated (Betolvex; Ratiopharm, $0.06 \mathrm{mg} / \mathrm{kg}$ orally q24h). Treatment for leishmaniosis was not started until 
Table 1 Summary of changes in clinical biochemistry parameters and results of additional diagnostic tests

\begin{tabular}{|c|c|c|c|c|c|c|c|c|c|c|}
\hline Serum parameter (reference interval) & FP & 1 MAFP & 2 MAFP & 4 MAFP & 7 MAFP & 10 MAFP & 17 MAFP & 24 MAFP & 32 MAFP & $\begin{array}{l}39 \\
\text { MAFP }\end{array}$ \\
\hline $\begin{array}{l}\text { Albumin } \\
(30-41 \mathrm{~g} / \mathrm{l})\end{array}$ & 25.7 & NT & 26.1 & 31.3 & 33.4 & 30.8 & 34.2 & 33.3 & 34.4 & 33.2 \\
\hline Total proteins $(58-77 \mathrm{~g} / \mathrm{l})$ & 53.0 & NT & 57.0 & 62.0 & 58.0 & 57.0 & 63.0 & 64.0 & 66.0 & 70.0 \\
\hline $\begin{array}{l}\text { Cobalamin } \\
(200-850 \mathrm{pg} / \mathrm{ml})\end{array}$ & 163 & NT & 737 & 1180 & NT & 176 & 766 & 839 & 904 & 725 \\
\hline $\begin{array}{l}\text { C-reactive protein } \\
(<10 \mathrm{mg} / \mathrm{l})\end{array}$ & 26.2 & 45.4 & $<10$ & NT & NT & NT & NT & NT & NT & NT \\
\hline Leishmania infantum antibodies $(<1: 32)$ & $1: 512$ & NT & NT & NT & NT & $1: 256$ & NT & NT & 1:64 & 1:64 \\
\hline
\end{tabular}

Values beyond the reference interval are bolded

FP First presentation, MAFP Months after the first presentation, NT Not tested

gastroduodenoscopy was performed and gastric biopsies examined.

Gastroduodenoscopy was performed one month after the first presentation since the dog did not improve after initiating treatment. The gastric mucosa of the corpus, fundus and proximal antrum was macroscopically irregular, showing cerebriform mucosal folds (Fig. 1a). The distal antrum (Fig. 1b) and duodenum were macroscopically unremarkable. Histopathological examination of the duodenum revealed a mild diffuse chronic lymphoplasmacytic enteritis with a mild multifocal neutrophilic component. Gastric mucosal biopsies showed a moderate multifocal chronic granulomatous gastritis with fewer lymphocytes and plasma cells (Fig. 1c) and occasional intralesional, round to ovoid, $3-6 \mu \mathrm{m}$ in diameter single-cell organisms, which were detected both within the cytoplasm of macrophages and extracellularly. In addition, severe manifestation of Helicobacterlike organisms (HLOs) and multifocal mild cystic dilatation of glands at the midlevel of the lamina propria were observed. The organisms seen intralesionally stained positively in both periodic acid Schiff's (PAS) and Grocott's methenamine silver special stainings.

A PCR for fungi was performed on a fresh frozen gastric mucosal biopsy sample (HUSLAB), and DNA from Malassezia globosa was found [10]. Leishmania spp. was examined by immunohistochemistry from a formalin fixed gastric biopsy (Universitat Autònoma de Barcelona) and by real-time PCR from a fresh frozen gastric biopsy (IDEXX Laboratories); both were negative [11]. Fluorescence in situ hybridization (FISH) from a formalin fixed gastric biopsy detected eubacteria, but no significant amounts of Escherichia coli, Salmonella spp., Helicobacter spp., Cryptococcus spp., Campylobacter spp., Leptospira spp. or Streptococcus spp. (Langford Vets Diagnostic Laboratories).

Based on these findings, the dog was treated for helicobacteriosis with amoxicillin (Amovet vet; Orion, $25 \mathrm{mg} / \mathrm{kg}$ orally q12h), clarithromycin (Clarithromycin Ratiopharm; Teva, $8 \mathrm{mg} / \mathrm{kg}$ orally q12h) and

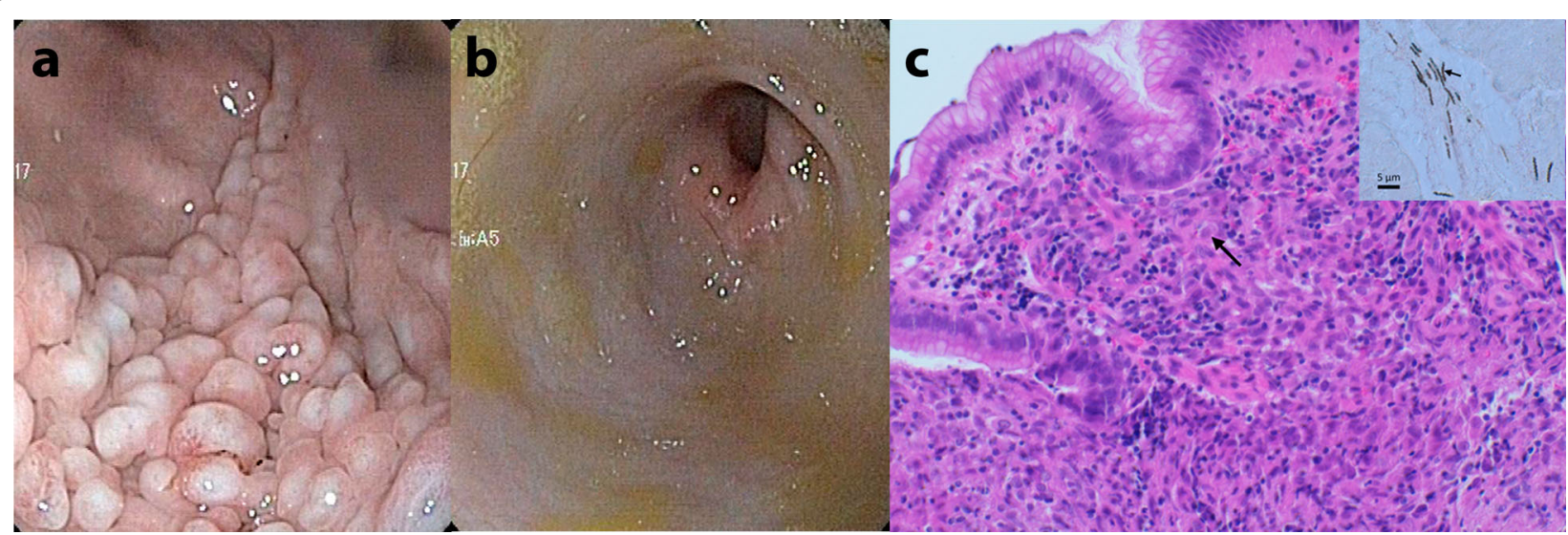

Fig. 1 First gastroduodenoscopy. a Endoscopic view of gastric corpus and proximal antrum showing cerebriform thickened gastric mucosal folds. b Endoscopic view of distal antrum and pylorus was macroscopically unremarkable. c Histopathology of the gastric mucosal biopsy showing multifocal moderately increased number of macrophages (arrow), lymphocytes and plasma cells. Haematoxylin and eosin staining 20X. Insert: Numerous spiral-shaped Helicobacter-like organisms (arrow) are present in gastric mucosa. Warthin-Starry silver staining, bar 5 um 
metronidazole (Metronidazol Ratiopharm; Ratiopharm, $8 \mathrm{mg} / \mathrm{kg}$ orally q12h) for two weeks. The palliative treatment continued with ondansetron and maropitant citrate, in addition to esomeprazole (Nexium; AstraZeneca, $1 \mathrm{mg} / \mathrm{kg}$ orally q24h). Oral supplementation of cobalamin was also continued.

One month later, the dog still vomited every other day. A second gastroduodenoscopy was performed. The gastric mucosal changes had the same magnitude and cerebriform appearance as in the first gastroduodenoscopy (Fig. 2a). Histopathological examination revealed a severe diffuse chronic lymphoplasmacytic gastritis with fewer macrophages. Some single-cell organisms were still present, but HLOs were no longer detected (Fig. 2b). The palliative treatment was continued. Based on the high antibodies against $L$. infantum antigens and persistent clinical signs, treatment for leishmaniosis was started according to LeishVet guidelines [12] with miltefosine (Milteforan; Virbac, $2 \mathrm{mg} / \mathrm{kg}$ orally q24h for 4 weeks) and allopurinol (Zyloric; Aspen, $10 \mathrm{mg} / \mathrm{kg}$ orally q12h).

One month later, the vomiting had stopped and the dog had gained weight. Serum total protein and albumin concentrations increased to the reference intervals, after which the oral cobalamin supplementation was discontinued. A third gastroduodenoscopy was performed. The macroscopically changed mucosal area was the same size and had the same appearance as during the first two endoscopies, but the mucosa was somewhat firmer (Fig. 3a). Histopathological examination now revealed a moderate diffuse chronic eosinophilic gastritis (Fig. 3b). Mild granulomatous inflammation was noted only focally in the corpus area. Single-cell organisms seen previously were no longer detected, but a small number of HLOs was seen. The palliative treatment and allopurinol were continued.

Seven months after the first presentation, the dog showed signs of heat for the first time after being spayed seven years earlier in Greece and was diagnosed ultrasonographically with an ovarian remnant on the left side. A laparotomy was performed and the ovarian remnant was removed and two full-thickness biopsies were taken from the gastric fundus and antrum. The aerobic and anaerobic bacterial culture of the gastric biopsies was negative. Histological examination of the fundic biopsy showed hyperplasia of the mucous cells within the neck and base areas of the fundic glands, multifocal cystic enlargement of mucinous glandular structures at the border between the lamina propria and lamina muscularis mucosae and loss of parietal and chief cells (Fig. 4). Occasional glandular structures were growing between the muscular bundles on the lamina muscularis mucosae. The fundic glandular changes were consistent with the histopathological findings described in MD. A mild multifocal granulomatous inflammation in the submucosa remained. There were no specific histopathological changes in the antral biopsy.

The dog had gained weight, achieving a normal body condition score (5/9), and with palliative treatment and

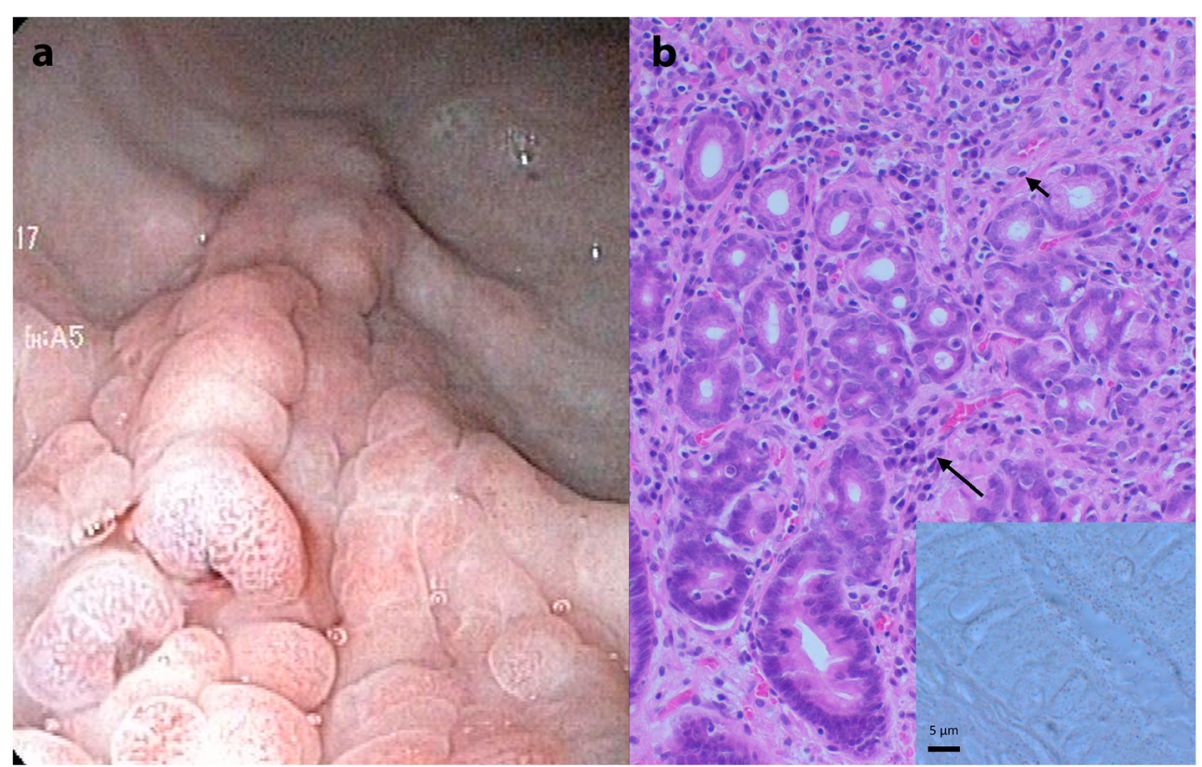

Fig. 2 Second gastroduodenoscopy. a Endoscopic view of the gastric corpus and proximal antrum showing the same giant cerebriform gastric mucosal folds as in the first endoscopy. $\mathbf{b}$ Histopathology of the gastric mucosal biopsy after treatment for Helicobacter-like organisms revealing a severe chronic diffuse lymphoplasmacytic gastritis (lymphocytes short arrow, plasma cells long arrow) with a decreased number of macrophages relative to the first gastric biopsies. Haematoxylin and eosin staining 20X. Insert: No Helicobacter-like organisms were detected. Warthin-Starry silver staining, bar $5 \mu \mathrm{m}$ 


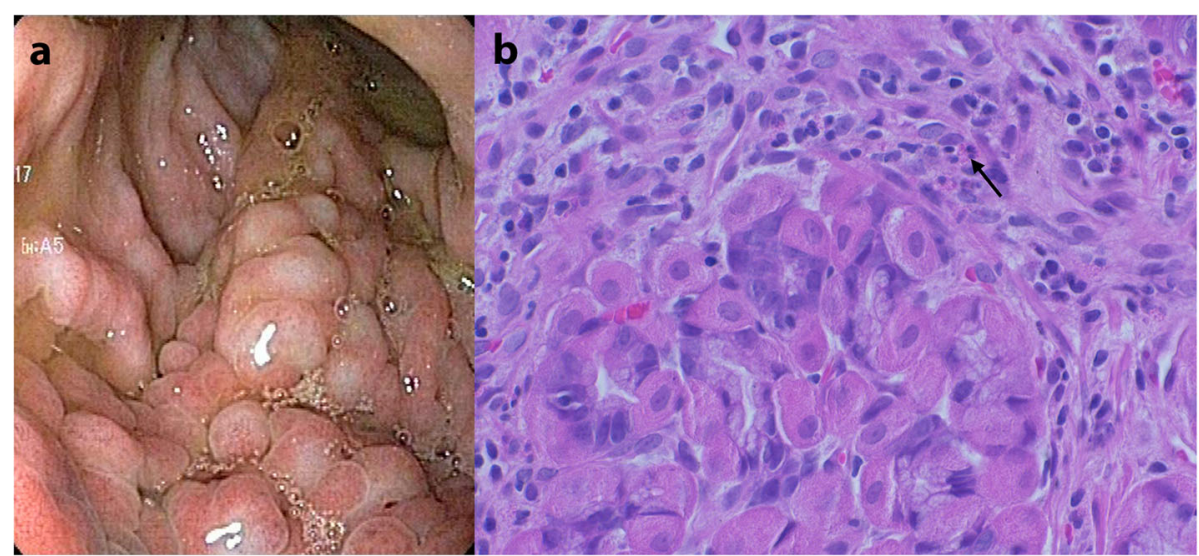

Fig. 3 Third gastroduodenoscopy. a Endoscopic view of the gastric corpus and proximal antrum showing the same giant cerebriform gastric mucosal folds as in the previous endoscopies. $\mathbf{b}$ Histopathology of the gastric mucosal biopsy revealed fundic glands surrounded by eosinophilic granulocytes (arrow), lymphocytes and plasma cells. Haematoxylin and eosin staining 40X.

allopurinol it had only vomited approximately twice a month. The palliative medications continued, but at a lower dose, with esomeprazole $0.7 \mathrm{mg} / \mathrm{kg}$ orally q24h, maropitant citrate $0.8 \mathrm{mg} / \mathrm{kg}$ orally $\mathrm{q} 24 \mathrm{~h}$ and ondansetron $0.3 \mathrm{mg} / \mathrm{kg}$ orally q24h. If any of the palliative medications were stopped or titrated down, the dog started vomiting again daily.

Ten months after the first examination, the dog developed hypocobalaminaemia again (Table 1), so cobalamin was started orally at $0.03 \mathrm{mg} / \mathrm{kg}$ q24h. Oral cobalamin supplementation was successful again (Table 1). Serum albumin concentration remained within the reference interval. Thirty-nine months after the first presentation, the dog was still on allopurinol, ondansetron and maropitant citrate and was vomiting approximately twice a month.

\section{Discussion and conclusions}

This case report describes the coexistence of two rare gastropathies in the dog, namely MLD and granulomatous gastritis, with simultaneous helicobacteriosis and leishmaniosis. The pathogenesis of MLD in dogs is unknown, but in MD in humans and mice, one factor is suggested to be increased signalling of EGFR [1]. Especially in children, MD is strongly associated with CMV infection, and CMV has been shown to activate EGFR signalling [2]. In CMV-associated cases, there is a spontaneous remission of MD [2]. Especially in adults, some MD cases have been associated with $H$. pylori infection and the eradication of $H$. pylori has resolved the endoscopic and histopathological findings [8]. In this dog, a severe manifestation of HLOs was present in the first mucosal biopsies of the stomach, which has not previously been reported in MLD cases in dogs [3-7].

The dog showed chronic upper gastrointestinal signs, such as weight loss, anorexia and vomiting in connection with hypoalbuminaemia, which are typical clinical signs for MLD in dogs and MD in humans [1, 3-5, 7]. In this case, vomiting slightly decreased when palliative treatment was initiated and later slightly more with

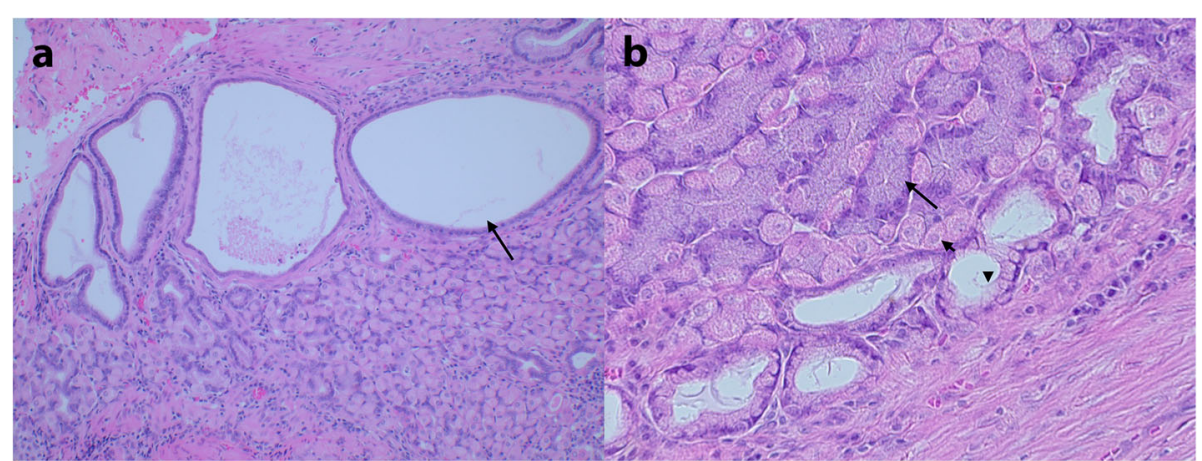

Fig. 4 Histopathology of the full-thickness biopsies of the fundus showing histopathological features of MD. a Cystic enlargement of mucinous glandular structures (arrow). Haematoxylin and eosin staining 10X. b Hyperplasia of the mucous cells (arrow head) and loss of parietal cells (short arrow) and chief cells (long arrow). Haematoxylin and eosin staining 40X. 
treatment for Helicobacter spp., but it did not cease. The Helicobacter spp. treatment also did not result in resolution of MLD. This could be explained with the chronic features of the dogs' disease. H. pylori -associated MD in humans going into remission, typically has an acute onset of symptoms [2]. After treatment for leishmaniosis, the vomiting ceased, the dog gained weight and the hypoalbuminaemia resolved. It seems likely that part of the clinical signs were caused by leishmaniosis. Six months after the miltefosine treatment, the antibody titres against $L$. infantum had halved, indicating that the leishmaniosis was in remission. The dog always started vomiting if any of the palliative treatment medications: maropitant citrate, ondansetron or esomeprazole, were stopped or titrated down. At this point, the vomiting was probably a sign of MLD.

In humans, treatments other than $H$. pylori eradication for MD have also been tried, such as antibiotics, steroids, acid suppressants, anticholinergic agents and octreotide therapy, but the findings have been inconsistent [2, 13]. In humans, promising results have been shown with cetuximab, a human monoclonal antibody that blocks EGFR signalling [1]. A "caninized" anti-EGFR antibody has been investigated only in vitro in canine cancer, however, no canine antiEGFR antibody is commercially available. Human anti-EGFR antibodies could cause adverse reactions in dogs such as anaphylaxis [14]. Partial or total gastrectomy has been done in cases with severe symptoms, and it has been reported to be a successful treatment also in two canine cases $[2,5,7,13]$. In this case, the affected area was too large to be removed surgically without affecting the function of the stomach; palliative treatment was given since the dog responded to it. Thirty-nine months after first presentation, the dog was clinically well, vomiting approximately twice a month, despite the low daily doses of the palliative treatments. Previously, the longest reported survival time in a dog not treated surgically was 27 months [6]. That dog had a subclinical disease for two years, but was given a gastric protectant, a proton pump inhibitor and a non-steroidal anti-inflammatory drug for an unknown period [6].

The dog here was hypocobalaminaemic and was supplemented orally with cobalamin [15]. The supplementation led to hypercobalaminaemia and was discontinued, after which the dog developed hypocobalaminaemia again. In dogs, aetiologies for hypocobalaminaemia are exocrine pancreatic insufficiency, chronic inflammatory enteropathies and alimentary lymphoma among others [16]. This dog showed no evidence of these diseases. In the stomach, free cobalamin is bound to haptocorrin, which in dogs is mostly produced by parietal cells in the gastric mucosa [17]. Haptocorrin is digested by pancreatic proteases in the duodenum and then free cobalamin is bound to intrinsic factor [16]. Intrinsic factor is mainly produced in dogs by the exocrine pancreas, but also in the stomach in parietal cells $[16,17]$. Parietal cells, which produce both haptocorrin and intrinsic factor, are typically lost in $\mathrm{MD}[1,16,17]$, which could be one possible factor contributing to the hypocobalaminaemia in this dog.

The serum gastrin concentration was measured to rule out gastrinoma as a differential diagnose for the hypertrophic changes in the stomach. The typical changes of MLD were not evident in the endoscopic gastric mucosal biopsies, but the diagnosis was achieved from the full-thickness biopsies. In humans, the diagnosis for MD is obtained from endoscopic biopsies, but large snare biopsies are recommended in macroscopically hypertrophic lesions, instead of standard forceps biopsies [2]. In the previous canine case reports, the diagnosis was made from full-thickness biopsies in all cases [3-7]. In one case, the first biopsies were taken by gastroscopy and they had contained only the superficial part of the mucosa from which the diagnosis of MLD could not be made [3]. In the case presented here, it is uncertain why the characteristic changes of MLD were not seen in the first three endoscopic mucosal biopsies because all samples had contained the lamina propria of the gastric mucosa and the macroscopic appearance of the gastric lesion at the endoscopies and the laparotomy had remained the same. Based on this, full-thickness biopsies should probably be the preferred method in dogs with suspected MLD. Full-thickness biopsies are also more accurate for the evaluation of possible neoplastic changes. People with MD have a higher risk of developing gastric neoplasia [1]. Four cases of MLD in dogs have been reported to progress to gastric carcinoma $[5,6]$. In three littermates, gastric adenocarcinoma was diagnosed [6]. In two of the dogs, the diagnosis was set at the same time as the diagnosis of MLD [6]. In the third dog, the diagnosis was made 27 months after diagnosis of MLD [6]. In one dog, a poorly differentiated superficial gastric carcinoma was diagnosed five years after a partial gastrectomy was done and MLD was diagnosed [5].

Granulomatous gastritis in dogs is far less common than lymphoplasmacytic or eosinophilic gastritis and has been described in rare cases of infections caused by fungi, parasites or bacteria [18]. The cause for the granulomatous gastritis in this dog was extensively examined, yet remained unknown. Granulomatous inflammation in the gastrointestinal tract of dogs in endemic areas of leishmaniosis has been reported in L. infantum infection [19]. However, L. infantum was not detected in the gastric biopsies by PCR or immunohistochemistry. The 
aerobic and anaerobic bacterial culture of the biopsy was negative. The PCR examination for fungi revealed a small amount of DNA from M. globosa. The PASpositive intralesional structures in the stomach were morphologically compatible with single-cell yeast. Malassezia spp. was not thought to be the cause for the granulomatous gastritis. The PAS-positive structures also disappeared from the biopsies without a treatment for Malassezia spp. FISH detected eubacteria within the gastric tissue samples, but not significant numbers of $E$. coli, Salmonella spp., Helicobacter spp., Cryptococcus spp., Campylobacter spp., Leptospira spp. or Streptococcus spp. It is unclear why the severe manifestation of HLO was not detected by FISH since in previous studies Helicobacter spp. have been detected by FISH with high sensitivity [20, 21]. In one study, Helicobacter spp. was detected by FISH in all gastric biopsies, but in a few biopsies from the small and large intestine they were not detected by FISH, even though Helicobacter spp. PCR had been positive [20]. This was thought to be associated with either a difficulty of the probes in penetrating the crypts or too few bacteria in the sample [20]. This could also be the case in our biopsies.

The role of Helicobacter spp. in the granulomatous gastritis of this dog is unknown. Typically, Helicobacter spp. infection in dogs manifests as mild lymphoplasmacytic gastritis, but can also be asymptomatic [22, 23]. In some human cases, it has been suggested that there might be an association between $H$. pylori infection and granulomatous gastritis $[24,25]$. In this case, the severity of the granulomatous gastritis markedly decreased after the treatment for Helicobacter spp, which supports a possible connection between the two conditions. However, we cannot exclude a response to the simultaneous treatment of leishmaniosis. Two months after the treatment, Helicobacter spp. were detected again in the gastric biopsies. Recurrence of gastric Helicobacter spp. after eradication is a common finding in dogs [26].

In conclusion, the dog was diagnosed with MLD, granulomatous gastritis, severe helicobacteriosis and leishmaniosis. The clinical signs decreased after treatment of helicobacteriosis and leishmaniosis, but mild chronic vomiting remained probably as a sign of MLD. The dog was doing well 39 months after the first presentation, which is the longest reported survival time for canine MLD with palliative treatment. Full-thickness biopsies are valuable in macroscopic hypertrophic lesions of the stomach for better assessment of the disease.

\footnotetext{
Abbreviations

CMV: Cytomegalovirus; EGFR: Epidermal growth factor receptor;

FISH: Fluorescence in situ hybridization; HLO: Helicobacter-like organism; MD: Ménétrier's disease; MLD: Ménétrier-like disease; PAS: Periodic acid Schiff's staining
}

\section{Acknowledgements}

The authors thank Pernilla Syrjä for fruitful cooperation in histopathological examinations and Jere Lindén for help with histopathological figures.

\section{Authors' contributions}

EL examined the patient several times and drafted the manuscript. SK and TS performed the gastroduodenoscopies and were major contributors to the writing of the manuscript. NA conducted the histopathological examinations of the stomach and wrote the sections about histopathological findings in the article. LSG analysed and interpreted the patient data regarding the $L$. infantum immunohistochemistry of the gastric biopsies. All authors read and approved the final manuscript.

\section{Funding}

No funding was received.

\section{Availability of data and materials}

All data are presented in the main paper and the accompanying figures.

Ethics approval and consent to participate

Not applicable.

\section{Consent for publication}

Consent for publication of the clinical details of the case was obtained from the dog's owner.

\section{Competing interests}

The authors have no competing interests to declare.

\section{Author details}

${ }^{1}$ Department of Equine and Small Animal Medicine, Faculty of Veterinary Medicine, University of Helsinki, P.O. Box 57, FI-00014 Helsinki, Finland. ${ }^{2}$ Department of Veterinary Biosciences, Faculty of Veterinary Medicine, University of Helsinki, P.O. Box 57, FI-00014 Helsinki, Finland. 'Departament de Medicina i Cirurgia Animals, Facultat de Veterinària, Universitat Autònoma de Barcelona, Bellaterra, 08193 Barcelona, Spain.

Received: 23 October 2020 Accepted: 16 February 2021

Published online: 02 March 2021

\section{References}

1. Fiske WH, Tanksley J, Nam KT, Goldenring JR, Slebos RJ, Liebler DC et al (2009) Efficacy of cetuximab in the treatment of Ménétrier's disease. Sci Transl Med 1(8):8ra18

2. Huh WJ, Coffey RJ, Washington MK (2016) Ménétrier's disease: its mimickers and pathogenesis. J Pathol Transl Med. 50:10-16

3. Van der Gaag I, Happé RP, Wolvekamp WT. A boxer dog with chronic hypertrophic gastritis resembling Menetrier's disease in man. Vet Pathol. 1976;13:172-85

4. Rallis TS, Patsikas MN, Mylonakis ME, Day MJ, Petanides TA, Papazoglou LG, et al. Giant hypertrophic gastritis (Ménétrier's-like disease) in an Old English sheepdog. J Am Anim Hosp Assoc. 2007:43:122-7.

5. Lecoindre P, Bystricka M, Chevallier M, Peyron C. Gastric carcinoma associated with Menetrier's-like disease in a West Highland white terrier. J Small Anim Pract. 2012;53:714-8.

6. Munday JS, Aberdein D, Cullen GD, French AF. Ménétrier disease and gastric adenocarcinoma in 3 Cairn terrier littermates. Vet Pathol. 2012;49:1028-31.

7. Vaughn DP, Syrcle J, Cooley J. Canine giant hypertrophic gastritis treated successfully with partial gastrectomy. J Am Anim Hosp Assoc. 2014;50:62-6.

8. Badov D, Lambert JR, Finlay M, Balazs ND. Helicobacter pylori as a pathogenic factor in Ménétrier's disease. Am J Gastroenterol. 1998;93: 1976-9.

9. Gold AJ, Langlois DK, Refsal KR. Evaluation of basal serum or plasma cortisol concentrations for the diagnosis of hypoadrenocorticism in dogs. J Vet Intern Med. 2016;6:1798-805.

10. Ala-Houhala M, Koukila-Kähkölä P, Antikainen J, Valve J, Kirveskari J, Anttila VJ. Clinical use of fungal PCR from deep tissue samples in the diagnosis of invasive fungal diseases: a retrospective observational study. Clin Microbiol Infect. 2018;24:301-5.

11. Casanova MI, Martín S, Marco A, Solano-Gallego L. Detection of Leishmania spp. infection by immunohistochemistry in archived biopsy samples from 
dogs with colitis in an area endemic for leishmaniosis. J Comp Pathol. 2019; 167:12-7.

12. Solano-Gallego L, Mirá G, Koutinas A, Cardoso L, Pennisi MG, Ferrer L, et al. LeishVet guidelines for the practical management of canine leishmaniosis. Parasit Vect. 2011;4:86.

13. Rich A, Toro TZ, Tanksley J, Fiske WH, Lind CD, Ayers GD, et al. Distinguishing Ménétrier's disease from its mimics. Gut. 2010;59:1617-24.

14. Singer J, Fazekas J, Wang W, Weichselbaumer M, Matz M, Mader A, et al. Generation of a canine anti-EGFR (ErbB-1) antibody for passive immunotherapy in dog cancer patients. Mol Cancer Ther. 2014;13:1777-90

15. Toresson L, Steiner JM, Suchodolski JS, Spillmann T. Oral cobalamin supplementation in dogs with chronic enteropathies and hypocobalaminemia. J Vet Intern Med. 2016;30:101-7.

16. Kather S, Grützner N, Kook PH, Dengler F, Heilmann RM. Review of cobalamin status and disorders of cobalamin metabolism in dogs. J Vet Intern Med. 2020;34:13-28.

17. Seetharam B, Alpers DH. Cobalamin binding proteins and their receptors. In: Dakshinamurti K, editor. Vitamin receptors: vitamins as ligands in cell communication. Cambridge: Cambridge University Press; 1994. pp. 78-105.

18. Amorim I, Taulescu MA, Day MJ, Catoi C, Reis CA, Carneiro F, Gärtner F. Canine gastric pathology: a review. J Comp Pathol. 2016;154:9-37.

19. Ruiz G, Laloy E, Benchekroun G. Chronic gastritis and enterocolitis associated with Leishmania infection in an 18-month-old, intact female dog. Vet Q. 2015;35:236-9.

20. Recordati C, Gualdi V, Craven M, Sala L, Luini M, Lanzoni A, Rishniw M, Simpson KW, Scanziani E. Spatial distribution of Helicobacter spp. in the gastrointestinal tract of dogs. Helicobacter. 2009;14:180-91.

21. Sharman M, Bacci B, Simpson K, Mansfield C. Comparison of in vivo confocal endomicroscopy with other diagnostic modalities to detect intracellular helicobacters. Vet J. 2016;213:78-83.

22. Neiger R, Simpson KW. Helicobacter infection in dogs and cats: facts and fiction. J Vet Intern Med. 2000;14:125-33.

23. Wiinberg B, Spohr A, Dietz HH, Egelund T, Greiter-Wilke A, McDonough SP, et al. Quantitative analysis of inflammatory and immune responses in dogs with gastritis and their relationship to Helicobacter spp. infection. J Vet Intern Med. 2005;19:4-14.

24. Kim YS, Lee HK, Kim JO, et al. A case of H. pylori-associated granulomatous gastritis with hypertrophic gastropathy. Gut Liver. 2009;3:137-40.

25. Koyama S, Nagashima F. Idiopathic granulomatous gastritis with multiple aphthoid ulcers. Intern Med. 2003;42:691-5.

26. Happonen I, Linden J, Westermarck E. Effect of triple therapy on eradication of canine gastric helicobacters and gastric disease. J Small Anim Pract. 2000; 41:1-6.

\section{Publisher's Note}

Springer Nature remains neutral with regard to jurisdictional claims in published maps and institutional affiliations.

Ready to submit your research? Choose BMC and benefit from:

- fast, convenient online submission

- thorough peer review by experienced researchers in your field

- rapid publication on acceptance

- support for research data, including large and complex data types

- gold Open Access which fosters wider collaboration and increased citations

- maximum visibility for your research: over $100 \mathrm{M}$ website views per year

At $\mathrm{BMC}$, research is always in progress.

Learn more biomedcentral.com/submissions 